This is an open access article distributed under the terms of the Creative Commons BY-NC-ND Licence

\title{
Shoot proliferation and organogenesis on Arbutus unedo: physiological analysis under water stress
}

\author{
J.F. MARTINS ${ }^{1 *}$, S. CORREIA ${ }^{1}$, B. CORREIA ${ }^{2}$, G. PINTO ${ }^{2}$, and J.M. CANHOTO ${ }^{1}$ \\ Centre for Functional Ecology, Universidade de Coimbra, 3000-456 Coimbra, Portugal ${ }^{1}$ \\ Department of Biology \& CESAM, University of Aveiro, 3810-193 Aveiro, Portugal ${ }^{2}$
}

\begin{abstract}
Strawberry tree (Arbutus unedo) is a small perennial tree that grows spontaneously in the Mediterranean basin, Ireland, and Portugal. In this work, strawberry tree clones were established in vitro from epicormic shoots obtained from a young tree, an adult tree, and from a seedling. They were propagated by axillary shoot buds proliferation on solid and in liquid media, and also in a modified De Fossard medium with $9 \mu \mathrm{M}$ benzylaminopurine. The organogenesis from calli obtained from apical leaves of the in vitro grown shoots from the three genotypes was carried out in the same basal liquid medium supplemented with $9 \mu \mathrm{M}$ thidiazuron. Micropropagation through organogenesis in liquid medium proved to be more efficient than the other tested methods (considering the number of shoots produced), but the shoots were showing hyperhydricity. Shoots were sucessufully rooted on medium with indole-3-butyric acid and acclimatized ex vitro with rates higher than $90 \%$. Six month-old plants from the most proliferative genotype (AU1) and propagated in vitro by different methods were submitted to drought stress (no watering for $10 \mathrm{~d}$ ) and several morphological and physiological parameters were evaluated and compared to a control group (watered to $70 \%$ field capacity). No significant differences were found in plant biomass, root length, and plant height, however, slight differences were observed in water potential, net photosynthetic rate, intercellular $\mathrm{CO}_{2}$ concentration, and stomatal conductance between the plantlets propagated on solid or liquid medium. In general, the responses to drought stress imposed were was similar in plants micropropagated by different propagation methods.
\end{abstract}

Additional key words: chlorophyll fluorescence, photosynthesis, stomatal conductance, strawberry tree, transpiration, water potential.

\section{Introduction}

Strawberry tree (Arbutus unedo L.) is an evergreen shrub or small tree $(3-8 \mathrm{~m})$ of the Ericaceae family native to the Mediterranean countries. It is also found in Portugal, Southern Ireland, and other regions where it has been introduced (Russell et al. 2007). Arbutus unedo is fairly tolerant to low temperatures $\left(-12^{\circ} \mathrm{C}\right)$ and drought (Piotto et al. 2001). These characteristics make A. unedo interesting from an ecological point of view since it can be grown in poor marginal lands where other plants hardly thrive. The ability to sprout following fires is also important (Quevedo et al. 2013). Strawberry tree fruits are round red berries and have interesting nutritional properties (Özcan and Haciseferoğullai 2007, RuizRodríguez et al. 2011, Miguel et al. 2014, Oliveira and Franco 2015). The fruits are mostly used in the production of a distilled beverage (Botelho and Galego 2015). The strawberry tree has been considered as neglected and underutilized crop (NUC) species. In order to meet the high yield expected by producers, selected and improved plant materials need to be available. For this reason, our group has been working on the micropropagation and breeding of A. unedo plants (Martins and Canhoto 2014,

Submitted 3 June 2018, last revision 8 October 2018, acepted 16 October 2018.

Abbreviations: BA - benzylaminopurine; $\mathrm{c}_{\mathrm{i}}$ - intercellular $\mathrm{CO}_{2}$ concentration; E - transpiration rate; $\mathrm{F}_{\mathrm{v}} / \mathrm{F}_{\mathrm{m}}$ - variable to maximum fluorescence ratio; $\mathrm{g}_{\mathrm{s}}$ - stomatal conductance; IBA - indole-3-butyric acid; $\mathrm{P}_{\mathrm{N}}$ - net photosynthetic rate; TDZ - thidiazuron; WS - water stress; WW - well watered; $\Psi$ - water potential; $\phi$ PS II - maximum yield of photosystem II.

Acknowledgments: Foundation for Science and Technology (Portugal) supported J. Martins PhD fellowship (SFRH/BD/122478/2016), G. Pinto (SFRH/BPD/101669/2014) and J. Canhoto (PTDC/AGR-FOR/3746/2012). The authors also acknowledge CESAM within PT2020 Partnership Agreement and Compete 2020 (UID/AMB/50017/2013-POCI-01-0145-FEDER-007638) and ReNATURE project (CENTRO-01-0145-FEDER-000007).

* Corresponding author; e-mail: joao.martins@uc.pt 
Martins et al. 2015, 2016). Several protocols for strawberry tree cloning through axillary shoot proliferation (Mereti et al. 2002, Gomes and Canhoto 2009, Gomes et al. 2010), and somatic embryogenesis (Martins 2012, Martins et al. 2015, 2016) have been developed. In this work, a new protocol for strawberry tree shoot proliferation in liquid medium and organogenesis was developed, and different micropropagation methods were tested, and their potential for mass scale propagation was evaluated. As referred by De Klerk and Ter Brugge (2011), these protocols are only profitable, from the economic point of view, if the performance of in vitro derived plants to field conditions is adequate. Water is the most limiting factor for plant acclimatization and growth on field conditions (Guarnaschelli et al. 2012) even in species recognized as drought tolerant as $A$. unedo (Munné-Bosch and Peñuelas 2004). Since strawberry tree orchards are usually established on dry and poor soils it is essential to assure drought tolerance of the micropropagated plants (Allen et al. 2010). Work done with strawberry tree wild plants on field conditions under water stress has shown that plants follow a conservative water use strategy (Castell and Terradas 1994, Ogaya et al. 2003, Munné-Bosch and Peñuelas 2004 ). However, and as far as we know, the performance of these plants obtained through micropropagation under water deficit conditions has not been tested before.

The main objective of this work was to compare different microprogation protocols for the production of strawberry tree and analyse the effect of these protocols on plant performance under drought stress.

\section{Materials and methods}

In vitro establishment: Three phenotypes of Abrutus unedo L. were selected: AU1 (young tree less than 5-yearold and a shrub-like growing type), AU2 (adult tree more than 10-year-old), and AU3 (seedling). The AU1 and AU2 were propagated in vitro using young branches from two different trees that were cut, dipped in $100 \mathrm{mg} \mathrm{dm}^{-3}$ fungicide Aliette (Bayer Cropscience, Carnaxide, Portugal) for $10 \mathrm{~min}$, and rinsed with distilled water. After this treatment, branches were kept in containers, covered with a plastic bag, watered with distilled water and placed in a culture chamber at a $16-\mathrm{h}$ photoperiod, an irradiance of $250 \mu \mathrm{mol} \mathrm{m} \mathrm{m}^{-2} \mathrm{~s}^{-1}$, a temperature of $25^{\circ} \mathrm{C}$, and an air humidity of $75 \%$ for $30 \mathrm{~d}$. The epicormic shoots formed were removed and surface sterilized with $70 \%(\mathrm{v} / \mathrm{v})$ ethanol $(30 \mathrm{~s})$ and $5 \%(\mathrm{~m} / \mathrm{v})$ calcium hypochlorite solution (Sigma-Aldrich, St. Louis, MO, USA) for $10 \mathrm{~min}$ with two drops of Tween 20. After 3 washes with sterile distilled water, the epicormic shoots $(0.5-1 \mathrm{~cm})$ were inoculated in a medium with De Fossard macronutrients and vitamins (De Fossard et al. 1974), Murashige and Skoog (1962; MS) microelements, $9 \mu \mathrm{M}$ benzylaminopurine (BAP; Sigma-Aldrrich), $3 \%$ (m/v) sucrose (Duchefa Biochemie, Haarlem, The Netherlands) and $0.6 \%(\mathrm{~m} / \mathrm{v})$ agar (Duchefa) and grown in test tubes $(25 \times 150 \mathrm{~mm})$ with plastic caps (Duran, Mainz, Germany). The culture medium was autoclaved at $121^{\circ} \mathrm{C}$ for $20 \mathrm{~min}$ and $\mathrm{pH}$ was adjusted to 5.7 using $\mathrm{KOH}$ or $\mathrm{HCl}$ before autoclaving and agar addition. For micro-propagation of AU3, seeds after 1 month of cold stratification $\left(4^{\circ} \mathrm{C}\right)$ were disinfected following a similar methodology as for shoots and germinated in Petri dishes on filter paper discs moistened with sterile distilled water in a growth chamber set to conditions mentioned above. The obtained seedlings were selected and multiplied by shoot proliferation in the medium described before.
Axillary shoot proliferation: For axillary shoot proliferation in solid medium (SM), AU1, AU2, and AU3 shoots were cultured in test tubes with $10 \mathrm{~cm}^{3}$ of the medium described before (one explant per tube and 30 tubes per test group). Shoot proliferation in liquid medium (LM) was carried out in Erlenmeyer flasks $\left(100 \mathrm{~cm}^{3}\right)$ with $25 \mathrm{~cm}^{3}$ of the same medium without the gelling agent ( 30 shoots were divided into 5 flasks for each test group). The flasks were placed on an orbital shaker $(80 \mathrm{rpm})$. The cultures were kept in a growth chamber, subculture intervals were 8 weeks. After 6 subcultures, micropropagation rates of the three genotypes were evaluated by the number of shoots longer than $1 \mathrm{~cm}$ obtained per initial explant.

Organogenesis: For micropropagation through organogenesis in liquid medium (LMO), calli with organogenic capacity were obtained from apical leaves from shoots obtained by shoot proliferation mentioned before. Leaves were cultured in the liquid medium described before, but supplemented with $9 \mu \mathrm{M}$ thidiazuron (TDZ; Sigma-Alrich), for a month (Martins and Canhoto 2014). Transversal cuts $(4-6)$ were made in the central part of the leaves, before they were placed with the abaxial side down on the culture medium. After 2 months, the obtained calli were transferred to liquid medium with the same composition and under the same conditions as for the shoot proliferatrion on liquid media.

Rooting and acclimatization: For root induction, $3 \mathrm{~cm}$ long shoots were cultured in test tubes, in a medium with KNOP salts (Gautheret 1959), De Fossard vitamins without riboflavin, MS microelements without KI, and $24.7 \mu \mathrm{M}$ indole-3-butyric acid (IBA; Sigma-Aldrich) at $25^{\circ} \mathrm{C}$ under the dark for $10 \mathrm{~d}$. Shoots were then transferred to a medium with the same composition but without IBA, 
$1 \%(\mathrm{~m} / \mathrm{v})$ charcoal (Sigma-Aldrich) was added and the shoots were grown in a growth chamber at a 16-h photoperiod, an irradiance of $15-20 \mu \mathrm{mol} \mathrm{m} \mathrm{m}^{-2} \mathrm{~s}^{-1}$ (coolwhite fluorescent lamps), and a temperature of $25^{\circ} \mathrm{C}$ for 3 weeks. Rooting rates were calculated and the number of roots per shoot was counted (only roots longer than $1 \mathrm{~mm}$ ), before plant acclimatization in covered containers with Perlite (Siro, Mira, Portugal) moistened with water in a culture chamber (FitoClima $10000 \mathrm{HP}$, Aralab, Portugal) under a 16-h photoperiod, an irradiance of $250 \mu \mathrm{mol} \mathrm{m} \mathrm{m}^{-2} \mathrm{~s}^{-1}$, a temperature of $25^{\circ} \mathrm{C}$, and $70 \%$ relative humidity. The container cover was gradually removed and after a month, acclimatization rates were calculated and plants transferred to individual $200 \mathrm{~cm}^{3}$ containers with peat and sand $(1: 1, \mathrm{v} / \mathrm{v})$.

Drought stress assays: From the acclimatized six-monthold plants, obtained by the three methods of in vitro propagation, with at least 10 well developed leaves, 6 plants were randomly chosen and placed under two water regimes: WW - well watered (watered to $70 \%$ field capacity) or WS - water stressed (without watering). After $10 \mathrm{~d}$ under these conditions plant performance was evaluated based on growth and physiological parameters. Only genotype AU1 was used in this assay, since it presented the highest multiplication rates at all propagation methods tested.

Root length and plant height were measured at the end of the WS period. Total plant dry mass was determined after drying the samples at $70^{\circ} \mathrm{C}$ until constant mass. Leaf area was determined using ImageJ (U.S. National Institutes of Health, Bethesda, Maryland, USA,

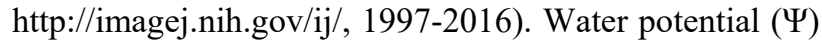
was measured with a Scholander-type pressure chamber (PMS Instrument Co., Albany, OR, USA). Plant water status was further assessed by the determination of the relative water content (RWC) calculated as [(fresh mass dry mass $) /($ water saturated mass - dry mass $)] \times 100$. Water saturated mass was determined after $24 \mathrm{~h}$ on distilled water at $4{ }^{\circ} \mathrm{C}$, and dry mass after drying at $70{ }^{\circ} \mathrm{C}$ for $48 \mathrm{~h}$.

In situ leaf gas exchange measurements (net photosynthetic rate, $\mathrm{P}_{\mathrm{N}}$, transpiration rate, $E$, intercellular $\mathrm{CO}_{2}$ concentration, $\mathrm{c}_{\mathrm{i}}$, and stomatal conductance, $\mathrm{g}_{\mathrm{s}}$ ) were performed on apical fully expanded leaves using a portable infrared gas analyser (LCpro + , ADC, Hoddesdon, UK) operating in open mode under the following conditions: irradiance of $350 \mu \mathrm{mol} \mathrm{m} \mathrm{m}^{-2} \mathrm{~s}^{-1}$, air flow of $200 \mathrm{~mol} \mathrm{~s}^{-1}$; block temperature of $25^{\circ} \mathrm{C}$, and atmospheric $\mathrm{CO}_{2}$ and $\mathrm{H}_{2} \mathrm{O}$ concentrations. Data were recorded when the measured parameters were stable (after 2 - 6 min).

A Chl $a$ fluorescence was determined in situ in fully expanded leaves, with a portable fluorimeter Mini-PAM (Walz, Effeltrich, Germany) as described by Jesus et al. (2015). Values of $\mathrm{F}_{\mathrm{v}} / \mathrm{F}_{\mathrm{m} .}=\left(\mathrm{F}_{\mathrm{m}}-\mathrm{F}_{0}\right) / \mathrm{F}_{\mathrm{m}}$ and $\Phi_{\mathrm{PSII}}=$ $\left(\mathrm{F}_{\mathrm{m}}^{\prime}-\mathrm{F}_{0}^{\prime}\right) / \mathrm{F}_{\mathrm{m}}^{\prime}$ were determined as described in this paper.

Statistical analysis: Values were given as means \pm standard deviantions of 30 replicates for micropropagation assays, and 6 replicates for drought stress. Micropropagation data were analyzed by one way ANOVA (GraphPad Prism for Windows v. 6.01), followed by a Tukey's multiple comparison test $(P<0.05)$. Comparisons of eco-physiological parameters of the plants submitted to two water regimes was done by a Student $t$-test.

\section{Results}

Strawberry tree was successfully micropropagated on solid and in liquid medium (Fig. 1A,B) and statistically significant differences were found in the number of shoots obtained in both treatments in the three genotypes tested (AU1, AU2, and AU3). However, the number of shoots obtained using organogenesis was substantially higher when compared to shoot proliferation. Although this difference was observed in all three tested genotypes, it was higher for genotype AU2, especially when compared to the propagation on solid medium, as the number of shoots obtained by organogenesis was almost 8 times higher $(15.57 \pm 2.21)$ compared to axillary shoot proliferation $(2.20 \pm 0.40$; Fig. $2 A)$. Despite the highest multiplication rates achieved, hyperhydricity was observed on some of the shoots obtained on liquid medium, either by shoot proliferation or organogenesis, causing phenotypic differences, such as abnormal leaf shape and lower chlorophyll content (data not show).

The rooting rates obtained were mostly higher than $80 \%$ in most of the groups tested and no statistically significant differences were observed among propagation

methods. Considering plants produced on solid medium the rooting rate was of $100 \%$ for genotype AU2. Moreover, the number of roots was similar on the plants produced on liquid and in solid medium, except in genotype AU2, where an average of $13.87 \pm 5.8$ roots was observed in shoots obtained on solid medium, compared to $5.2 \pm 0.8$ in liquid medium (Fig. 2C). Throughout the rooting process, most of the plants showing hyperhydricity and corresponding modifications recovered their normal phenotype.

In all groups, most of the plants survived after the acclimatization (Fig. 1C), and no differences were found among propagation methods, with rates higher than $80 \%$, except for plants produced through organogesis from genotype AU3, established in vitro from a seedling (Fig. 2D). Three months after acclimatization, the plant height and leaf area of those obtained by shoot proliferation, both in solid and on liquid medium, was very similar. However, the plants obtained through organogenesis showed lower height (Fig. 3A) and smaller leaf area (for genotypes AU2 and AU3, Fig. 3B). 
Mostly no significant differences were found in total plant biomass, height and root lenght under WW and WS regimes (Fig. $4 D-F$ ) in plants obtained by different micropogation methods. Similar results were also obtained regarding leaf area, although sligtly less values were found for plants propagated on solid medium (Fig. 4C).

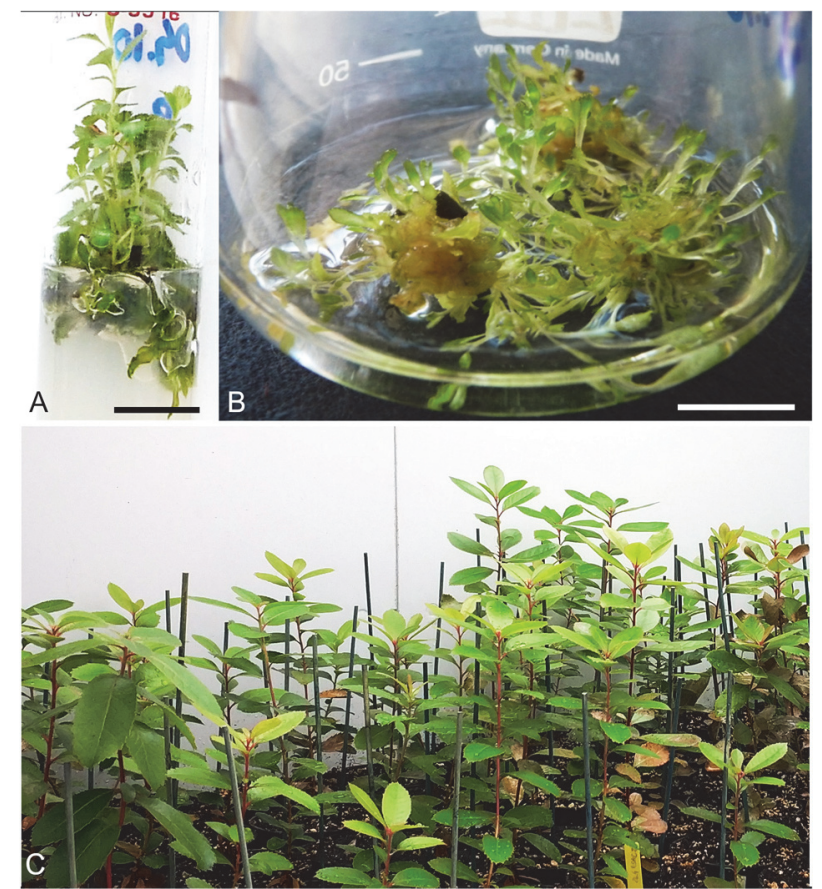

Fig. 1. Micropropagation of strawberry tree by axillary shoot proliferation on solid medium $(A)$ or by organogenesis in liquid medium $(B)$, and ex vitro acclimatized plants after three months $(C)($ bar $=1 \mathrm{~cm})$.

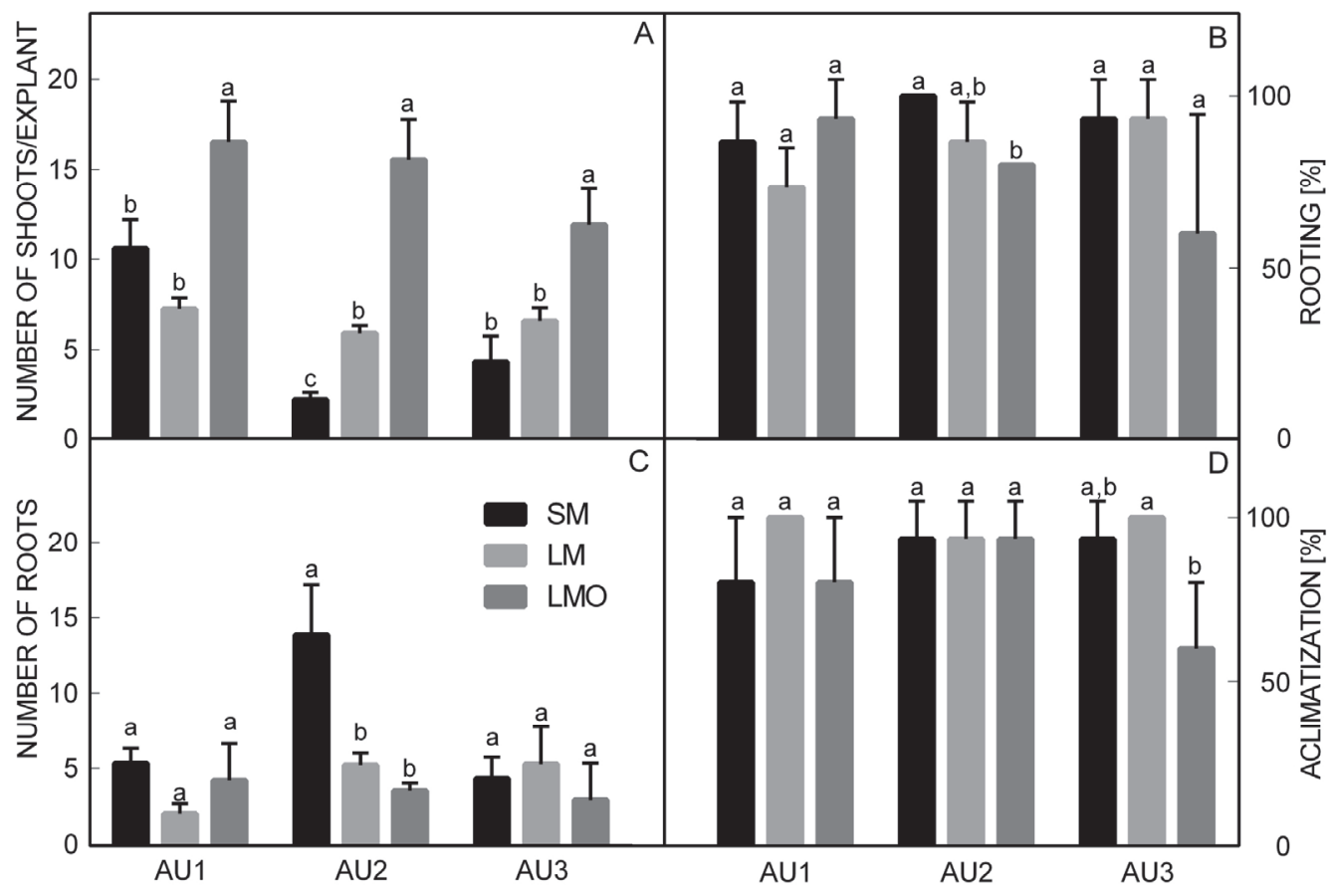

Fig. 2. Number of shoots per explants $(A)$, rooting rate $(B)$, number of roots per plantlet $(C)$, and acclimatization percentage $(D)$ in genotypes AU1, AU2, and AU3 by using three micropropagation methods (SM - axillary shoot proliferation on solid medium, LM axillary shoot proliferation on liquid medium, $\mathrm{LMO}$ - organogenesis on liquid medium). Means $\pm \mathrm{SDs}, n=3$, on each genotype different letters indicate significant differences between treatments at $P \leq 0.05$. 
Water potential was lower on plants under drought stress conditions, when compared to well-watered plants. However, it was statistically different only for plants produced in liquid medium by axillary shoot proliferation
(Fig. 4A) check values!.Very slight differences were found in RWC and only in plants propagated on solid medium (Fig. 4B).

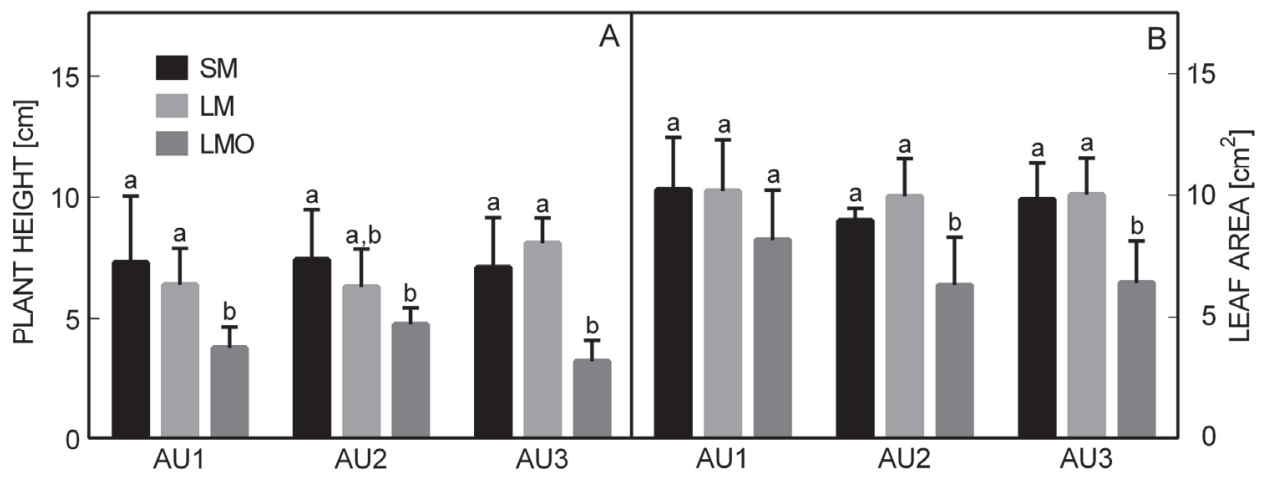

Fig. 3. Effect of three micropropagation methods (SM - axillary shoot proliferation on solid medium, LM - axillary shoot proliferation on liquid medium, LMO - organogenesis on liquid medium) on height $(A)$ and leaf area $(B)$ of plants of different genotypes (AU1, AU2, and AU3) measured three months after acclimatization. Means \pm SDs, $n=3$, different letters indicate significant differences between treatments at $P \leq 0.05$.

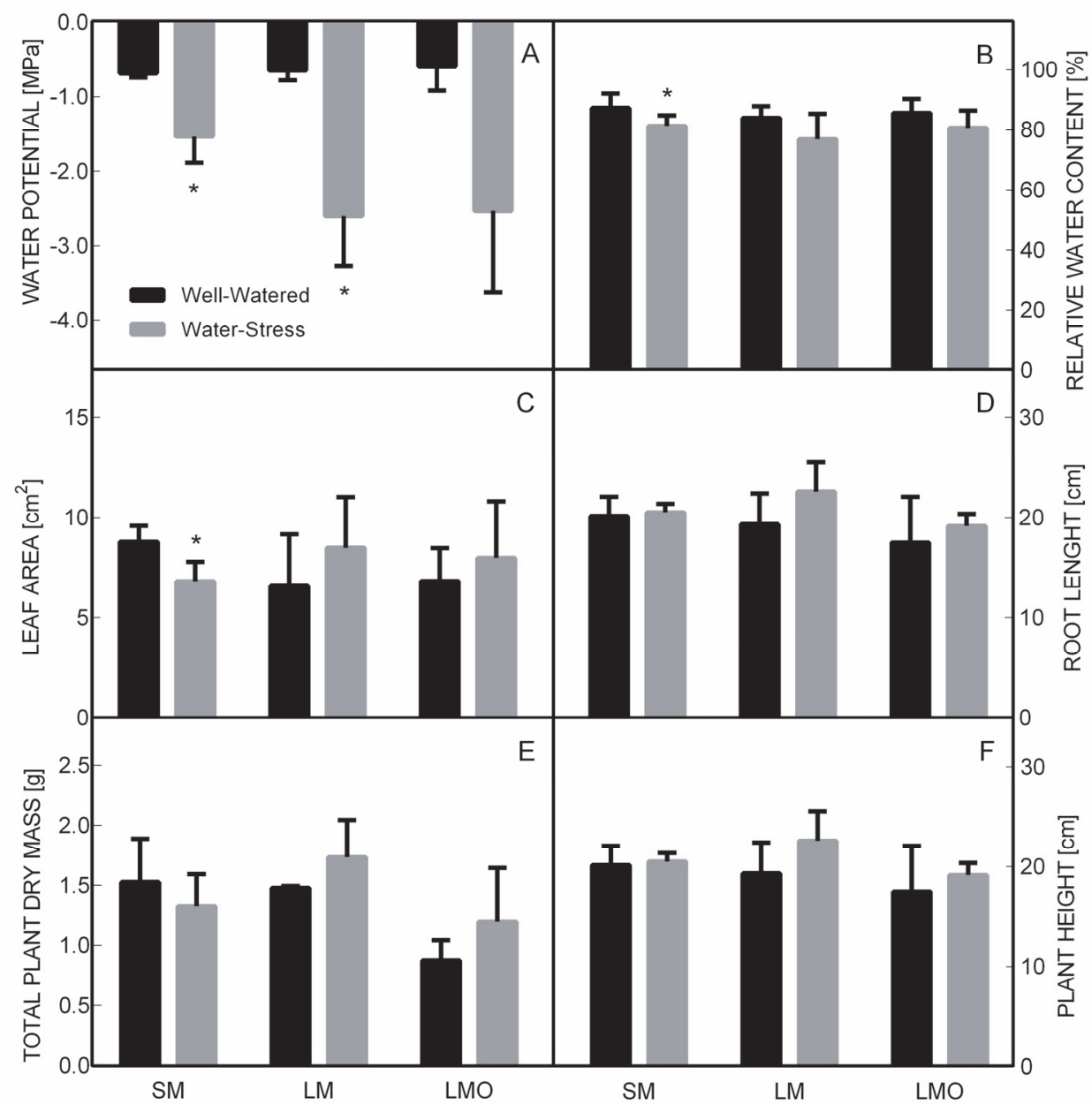

Fig. 4. Effects of water stress (WS) imposed to AU1 plants propagated by three methods (SM - axillary shoot proliferation on solid medium, LM - axillary shoot proliferation on liquid medium, LMO - organogenesis on liquid medium) and acclimatized for 6 month on water potential $(A)$, relative water content $(B)$, leaf area $(C)$, root length $(D)$, total plant dry mass $(E)$, and plant height $(F)$ in comparison with well watered plants (WW). Means $\pm \mathrm{SDs}, n=5$, , indicate significant differences between treatments at $P \leq 0.05$. 
As concern gas exchange parameters, stomatal conductance, intercellular $\mathrm{CO}_{2}$ concentration, and net photosynthetic rate (Fig. 5ACD) were decreased under water deficit, especially when the plants were obtained by axillary shoot proliferation on solid and liquid medium. No marked differences were found in transpiration rates
(Fig. 5B). The chlorophyll fluorescence parameters, the yield of photosystem II under steady-state conditions and maximum efficiency of photosystem II were very similar in all treatments (Fig. 5E,F). Only a slight increase in $\phi$ PS II was observed for plants from solid medium when submitted to water stress.

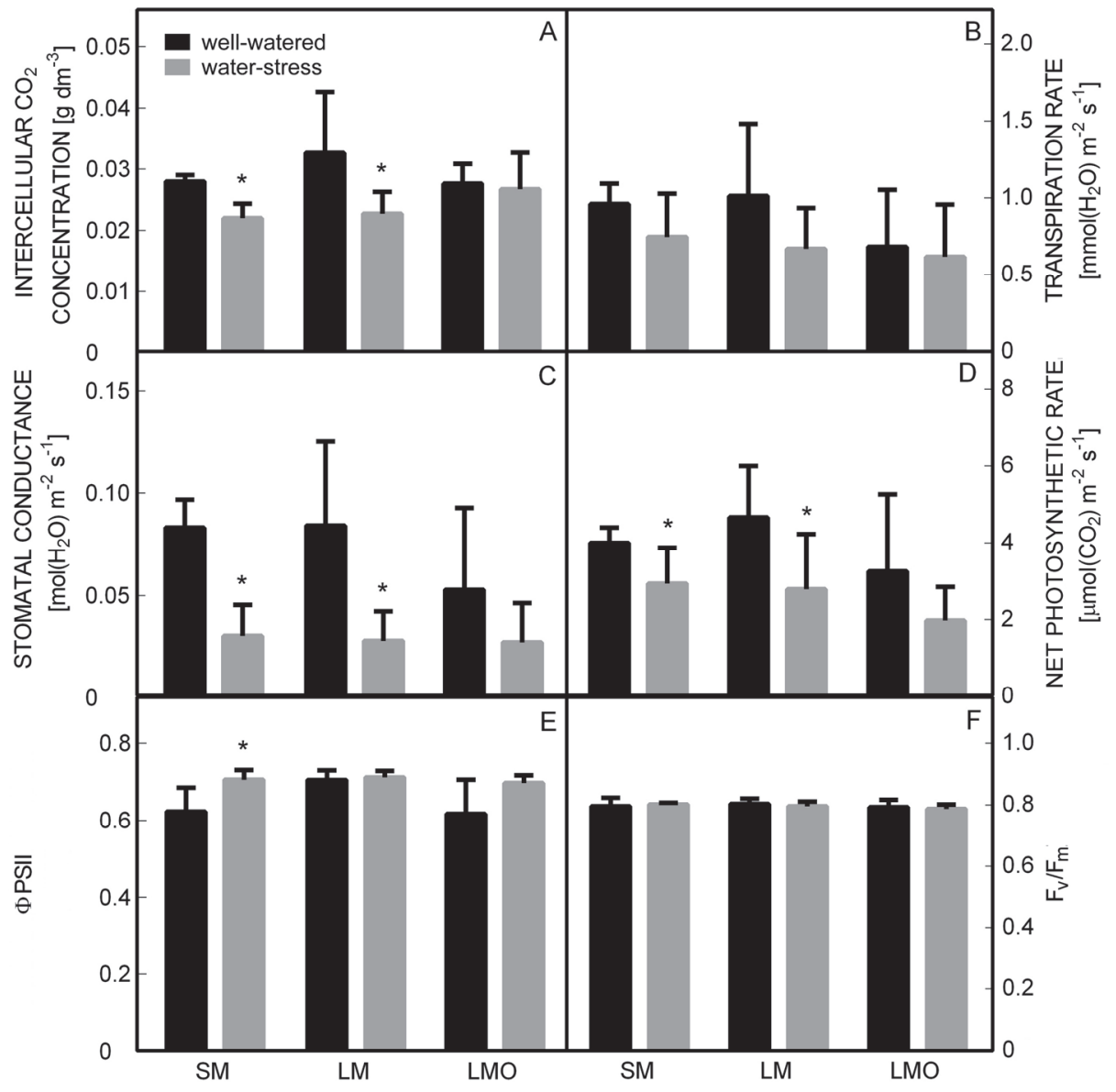

Fig. 5. Effects of water stress (WS) imposed to AU1 plants propagated by three methods (SM - axillary shoot proliferation on solid medium, LM - axillary shoot proliferation on liquid medium, LMO - organogenesis on liquid medium) and acclimatized for 6 month on intercellular $\mathrm{CO}_{2}$ concentration $(A)$, transpiration rate $(B)$, stomatal conductance $(C)$, net photosynthetic rate $(D)$, and chlorophyll fluorescence parameters quantum yield of photosystem II $(E)$ and photochemical efficincy of PS II $(F)$ in comparison with well watered plants (WW). Means \pm SDs, $n=5,{ }^{*}$ indicate significant differences between treatments at $P \leq 0.05$.

\section{Discussion}

The protocol developed for the micropropagation of strawberry tree in liquid medium was proved to be very efficient. Similar results have been reported for some other species, such as Camellia sinensis (Sandal et al. 2001), Dioscorea japonica (Kadota and Niimi 2004), and Catharanthus roseus (Pati et al. 2011). These kinds of protocols tend to be more effective when compared to the ones on solid medium in terms of proliferation rates, shoot size, and biomass. This might be related to a more efficient uptake of nutrients due to the large area of contact with the medium, since nutrients can be uptaken also by leaves via stomata and aqueous pores (De Klerk and Ter Brugge 2011) and even through the cuticule, which in leaves of in vitro growing shoots or plantlets is thin and may allow the change between the culture medium and plant tissues (Dias Ferreira et al. 2003). However, some of the drawback observed on strawberry tree, particularly the hyperhydricity of shoots, were also mentioned previously (Sandal et al. 2001, Kadota and Niimi 2004, Pati et al. 2011). Although some phenotypic differences were observed in strawberry tree plants produced in liquid medium either by shoot proliferation or organogenesis 
(Martins and Canhoto 2014), they were only a transitory and according to the parameters evaluated six-month after ex vitro transfer, they did not affect overall plant performance when submitted to drought stress.

The genotype plays and important role on micropropagation, as it has already been reported for strawberry tree (Gomes et al. 2010) as well as for other species such as Paeonia suffruticosa (Beruto et al. 2004) and Hagenia abyssinica (Feyissa et al. 2005). Our results show that organogenesis was the most effective method for the propagation of all strawberry tree genotypes. However, the results also show that different genotypes behaved differently accordingly to micropropagation method tested. For example, all the genotypes seemed to display no differences when the organogenesis was used whereas more clear differences were found when shoot proliferation was used. This might be due to inadequate culture conditions for specific genotypes, such as medium $\mathrm{pH}$ or nutrient composition as well as added plant growth regulators (Gomes et al. 2010). The age of the mother plant, as well as its physiological condition, may also be important factors for micropropagation efficiency (Chowdhury et al. 2004, Shukla et al. 2013). In fact, genotype AU1 (established in vitro from a young tree), has higher micropropagation rate by axillary shoot proliferation on solid medium when compared to genotype AU2, whose mother plant is an older tree.

In the present study, no significant morphological differences were observed among the plants acclimatized ex vitro for 6 months, which were originally obtained by the different micropropagation methods and also when they were submitted to different water regimes. A reduction in growth was reported in previous studies when strawberry tree plants and seedlings were submitted to a water deficit (Ogaya et al. 2003, Ogaya and Peñuelas 2004, Vasques et al. 2013). This is a common response to dry environments, as plants tend to increase belowground biomass allocation in order to improve water uptake. However, no differences were observed in this assay in terms of biomass allocation, probably due to the short duration of the experiment because some time is required to activate the complex mechanisms induced by drought stress (Chaves 2002, Chambel et al. 2005). Despite that, a slight reduction in leaf area was observed in plants produced by shoot proliferation on solid medium when submitted to water limitation. The reduced investment in foliar area is a relevant strategy to cope with water deficit conditions (Lopez et al. 1997).

In general, the physiological parameters evaluated in plants produced by different propagation methods were not significantly different after imposition of mild water stress, and were in accordance with the values previously reported (Castell and Tarradas 1994, Vasques et al. 2013). Many of them were not significantly different between two water regimes. However, the water potential was significantly reduced in plants produced by shoot proliferation in the solid medium. Plants obtained by the other two methods were probably more dynamic in maintaining the physiological traits, which are particularly important for breeding drought-tolerant plants.

The stomatal conductance was lower in plants submitted to water stress, with a statistically significant difference for plants produced by shoot proliferation in the solid and liquid medium, which may indicate a better performance of plants produced by this technique, to be tested on future research. In fact, plants have evolved several mechanisms in order to adapt to unfavourable environmental conditions by reducing resources consumption and adjusting their growth (Osakabe et al. 2014). In water deficit conditions, changes in ion- and water-transport systems across membranes in guard cells stimulates stomatal closure, which directly affects photosynthetic rates and plant productivity due to lower levels of $\mathrm{CO}_{2}$ available (Osakabe et al. 2014). According to previous reports (Castell and Terradas 1994, Gratani and Varone 2004, Navarro-García et al. 2011), the reduction of stomatal conductance usually occurs under drought stress as part of the efficient water use strategy of strawberry tree (Castell and Terradas 1994, Gratani and Varone 2004, Navarro-García et al. 2011), a typical drought resistant sclerophyllous Mediterranean species. Activation of antioxidative protection mechanisms has also been reported as a mechanism that might be used by this species to cope with water stress (Munné-Bosch and Peñuelas 2004).

The micropropagation in liquid medium was found very efficient for strawberry tree, especially by organogenesis, in the three genotypes tested. Nevertheless, strawberry trees micropropagated by different methods showed a very similar morphological and physiological performance and were not strongly affected under the imposed drought stress. However, plants produced by shoot proliferation on solid medium showed a slightly superior performance in some of the evaluated parameters, indicating different adaptation strategies to the imposed water stress, that should be taken into account when selecting a propagation technique. Overall, we can conclude that the tested propagation methods were efficient and did not considerably affect plant performance and productivity and can be used for strawberry tree micropropagation.

\section{References}

Allen, C., Macalady, A., Chenchouni, H., Bachelet. D., McDowell, N., Vennetier, M., Kitzberger, T., Rigling, A., Breshears, D., Hogg, E., Gonzalez, P., Fensham, R., Zhang,
Z., Castro, J., Demidova, N., Lim, J., Allard, G., Running, S., Semerci, A., Cobb, N.: A global overview of drought and heat-induced tree mortality reveals emerging climate change 
risks for forests. - Forest Ecol. Manage. 259: 660-684, 2010.

Beruto, M., Lanteri, L., Portogallo, C.: Micropropagation of tree peony (Paeonia suffruticosa). - Plant Cell Tissue Organ Cult. 79: 249-255, 2004.

Botelho, G., Galego, L.: [Good practices on the production of strawberry tree dislilates]. - Instituto Politécnico de Coimbra, Escola Superior Agrária, CERNAS, Coimbra 2015.[In Port.]

Castell, C., Terradas, J.: Effects of water and nutrient availability on water relations, gas exchange and growth rate of mature plants and resprouts of Arbutus unedo L. - Ann. Bot. 73: 595602, 1994.

Chambel, M.R., Climent, J., Alía, R., Valladares, F.: Phenotypic plasticity: a useful framework for understanding adaptation in forest species. - Invest. Agr. Sit. Recur. Forest. 14: 334344, 2005.

Chaves, M.: How plants cope with water stress in the field? Photosynthesis and growth. - Ann. Bot. 89: 907-916, 2002.

Chowdhury, P., Das, M., Sikdar, S., Pal, A.: Influence of the physiological age and position of the nodal explants on micropropagation of field-grown Dendrocalamus strictus Nees. - Plant Cell Biotech. mol. Biol. 5: 45-50, 2004.

De Fossard, R.A., Nitsch, C., Cresswell, R.J., Lee, C.M.: Tissue and organ culture of Eucalyptus. - New Zeal. J. Forest. Sci. 4: 267-278, 1974.

De Klerk, G.J., Ter Brugge, J.: Micropropagation of dahlia in static liquid medium using slow-release tools of medium ingredients. - Sci. Hort. 127: 542-547, 2011.

Dias Ferreira, C., Dias, J.D., Canhoto, J.M.: In vitro propagation of Leucadendron laureolum $\times$ L. salignum cv. Safari Sunset: Ultrastructural and anatomical studies of regenerated plantlets. - Acta horticult. 602: 29-38, 2003.

Feyissa, T., Welander, M., Negash, L.: Micropropagation of Hagenia abyssinica: a multipurpose tree. - Plant Cell Tissue Organ Cult. 80: 119-127, 2005.

Gautheret, R.J.: La culture des tissues végétaux, techniques et réalisations. [Plant Tissue Culture Techniques] - Masson, Paris 1959. [In French]

Gomes, F., Canhoto, J.M.: Micropropagation of strawberry tree (Arbutus unedo L.) from adult plants. - In Vitro Cell Dev. Biol. Plant 45: 72-82, 2009.

Gomes, F., Simões, M., Lopes, M.L., Canhoto, J.M.: Effect of plant growth regulators and genotype on the micropropagation of adult trees of Arbutus unedo L. (strawberry tree). - New Biotechnol. 27: 882-892, 2010.

Gratani, L., Varone, L.: Adaptative photosynthetic strategies of the Mediterranean maquis species according to their origin. Photosynthetica 42: 551-558, 2004.

Guarnaschelli, A.B., Garau, A.M., Lemcoff, J.H.: Water Stress and afforestation: a contribution to ameliorate forest seedling performance during the establishment. - In: Ismail, M., Rahman, M. (ed.): Water Stress. Pp. 73-110. InTech, location? 2012.

Jesus, C., Meijón, M., Monteiro, P., Correia, B., Amaral, J., Escandón, M., Pinto, G.: Salicylic acid application modulates physiological and hormonal changes in Eucalyptus globulus under water deficit. - Environ. exp. Bot. 118: 56-66, 2015.

Kadota, M., Niimi, Y.: Improvement of micropropagation of Japanese yam using liquid and gelled medium culture. - Sci. Hort. 102: 461-466, 2004.

Lopez, F.B., Chauhan, Y.S., Johansen, C.: Effects of drought stress on leaf area development and canopy light interception of short-duration pigeonpea. - J. Agron. Crop. Sci. 178: 1-7, 1997.
Martins, J.F.: [In vitro culture and breeding of strawberry tree]. Dissertation, University of Coimbra 2012.[In Port.]

Martins, J.F., Canhoto, J.M.: [Strawberry tree (Arbutus unedo L.) biotechnology: in vitro culture and breeding]. - Acta Port. Horticult. 23: 494-499, 2014.[In Port.]

Martins, J.F., Correia, S.I., Canhoto, J.M.: Somatic embryogenesis induction and plant regeneration in strawberry tree (Arbutus unedo L.). - In: Germana, M., Lambardi, M. (ed.): In Vitro Embryogenesis in Higher Plants. (Methods in Molecular Biology. Vol. 1359). Pp. 329-338. Humana Press, New York 2015.

Martins, J.F., Santos, T., Correia, S.I., Canhoto, J.M.: Somatic embryogenesis in Arbutus unedo L. and other Ericaceae. In: Park, Y.S., Bonga, J., Moon, H.K. (ed.): Vegetative Propagation of Forest Trees. Pp. 491-514. National Institute of Forest Science, Seoul 2016.

Mereti, M., Grigoriadou, K., Nanos, G.D.: Micropropagation of the strawberry tree, Arbutus unedo L. - Sci. Hort. 93: 143148, 2002.

Miguel, M.G., Faleiro, M.L., Guerreiro, A.C., Antunes, M.D.: Arbutus unedo L.: chemical and biological properties. Molecules 19: 15799-15823, 2014.

Munné-Bosch, S., Penuelas, J.: Drought-induced oxidative stress in strawberry tree (Arbutus unedo L.) growing in Mediterranean field conditions. - Plant Sci. 166: 1105-1110, 2004.

Murashige, T., Skoog, F.: A revised medium for rapid growth and bioassays with tobacco tissue cultures. - Physiol. Plant. 15: 473-497, 1962.

Navarro-García, A., Árias, S.P.B., Morte, A., Sánchez-Blanco, M.J.: Effects of nursery preconditioning through mycorrhizal inoculation and drought in Arbutus unedo L. plants. Mycorrhiza 21: 53-64, 2011.

Ogaya, R., Peñuelas, J.: Phenological patterns of Quercus ilex, Phillyrea latifoli, a and Arbutus unedo growing under a field experimental drought. - Ecoscience 11: 263-270, 2004.

Ogaya, R., Peñuelas, J., Martínez-Vilalta, J., Mangirón, M.: Effect of drought on diameter increment of Quercus ilex, Phillyrea latifolia, and Arbutus unedo in a holm oak forest of NE Spain. - Forest. Ecol. Manage. 180, 175-184, 2003.

Oliveira, M.F., Franco, J.: Analysis of potentialities for the consumption of fresh strawberry tree fruits: preliminary results. - In: Dumitras, D.E., Jitea, I.M., Aerts, S. (ed.): Know Your Food: Food Ethics and Innovation. Pp. 241-2481. Wageningen Academic Publishers, Wageningen 2015.

Osakabe, Y., Osakabe, K., Shinozaki, K., Tran, L.-S.P., Testerink, C.: Response of plants to water stress. - Front. Plant Sci. 5: 86, 2014.

Özcan, M.M., Haciseferoğullari, H.: The strawberry (Arbutus unedo L.) fruits: chemical composition, physical properties and mineral contents. - J. Food Eng. 78: 1022-1028, 2007.

Pati, P.K., Kaur, J., Singh, P.: A liquid culture system for shoot proliferation and analysis of pharmaceutical active constituents of Catharanthus roseus (L.) G. Don. - Plant Cell Tissue Organ Cult. 105: 299-307, 2001.

Piotto, B., Piccini, C., Arcadu, P.: [Vegetation recovery after fires at the Mediterranean region]. - In: Piotto, B., Noi, A. (ed.): [Seed Propagation of Mediterranean Trees and Shrubs]. Pp. 32-38 Dipartimento Prevenzione e Risanamento Ambientali. Manuale ANPA (Agenz. Naz. per la Protezi. dell'Ambiente) 2001.[In Ital.]

Quevedo, L., Arnan, X., Rodrigo, A.: Selective thinning of Arbutus unedo coppices following fire: effects on growth at 
the individual and plot level. - Forest Ecol. Manage. 292: 5663, 2013.

Ruiz-Rodríguez, B.-M., Morales, P., Fernández-Ruiz, V., Sánchez-Mata, M.-C., Díez-Marqués, C., Pardo-deSantayana, M., Molina, M., Tardio, J.: Valorization of wild strawberry-tree fruits (Arbutus unedo L.) through nutritional assessment and natural production data. - Food Res. Int. 44: 1244-1253, 2011.

Russell, T., Cutler, C., Walters, M.A.: The Illustrated Encyclopedia of Trees of the World. - Hermes House, Anenss Publishing, London 2007.

Sandal, I., Bhattacharya, A., Ahuja, P.: An efficient liquid culture system for tea shoot proliferation. - Plant Cell Tissue Organ
Cult. 65: 75-80, 2001.

Shukla, M., Sullivan, J.A., Jain, S.M., Murch, S.J., Saxena, P.K.: Micropropagation of African violet (Saintpaulis ionantha Wendl.). - In: Lambardi, M., Ozudogru, E.A., Jain, S.M. (ed.): Protocols for Micropropagtion of Selected Economically Important Horticultural Plants. (Methods in Molecular Biology. Vol. 994.) Pp. 279-289. Humana Press, New York 2013.

Vasques, A., Chirino, E., Vilagrosa, A., Ramón-Vallejo, V., Jacob Keizer, J.: The role of seed provenance in the early development of Arbutus unedo seedlings under contrasting watering conditions. - Environ. exp. Bot. 96: 11-19, 2013. 